\title{
Active seniors and old farts
}

\section{Moral experiments between improvement, decline and the end of life in old age}

\section{Louise Scheel Thomasen}

Konsulent

lsthomasen@gmail.com

Thomasen, Louise Scheel (2018). 'Active seniors and old farts: Moral experiments between improvement, decline and the end of life in old age' i Tidsskrift for Forskning i Sygdom og Samfund, nr. 30. 91-106.

Based on ethnographic fieldwork among elderly people in physical rehabilitation in Denmark, the article examines aging with disease and frailty as a process of moral becoming. Employing Cheryl Mattingly's notion of Moral Laboratory (Mattingly 2014), the article shows how life in old age, when changed by disease and the onset of frailty, is marked by striving, failure and success in the endeavour to create a good life in a constant negotiation with the body that seems to have grown a will of its own. In the training centers the body is a malleable and controllable entity known through tests and training routines, underlining individual responsibility and an active senior life as a moral value. The body does not necessarily comply with the defined goals, and other possible futures come into play, where 'old age' can be an explanatory resource in accepting frailty as part of life and the end of life rehearsed and orchestrated.

\section{Introduction}

This article is about elderly people living with disease and other health complications and how they strive to create a good life for themselves in a constant ne- 
gotiation with the body. In this process, they draw on diverging moral virtues concerning bodies and ageing, pertaining to different social and moral settings. The analysis brings the body to the foreground, underlining morality as an embodied practice.

As part of an ethnographic fieldwork I followed physical rehabilitation for elderly people in two training centers in a Danish municipality, watching how even simple movements - standing on one's toes, walking sideways, getting up and down from a chair or walking the stairs - would be a major challenge. Their reason for attending the training varied - some elderly came from the hospital after having an operation in the hip or the knee, others would enter the training center for other reasons, having gone through a decline in health and functional abilities over time, perhaps falling ill continuously and not being able to get 'back up' again.

Not everyone were able to get 'back up' though. At times attendance would falter over a couple of weeks, sometimes a training course would be stopped abruptly. At times people would return after a few months, once again having dropped to a worsened state of physical functioning. Following people outside the training centers it became clear how other moral virtues than staying active and improving the frail body would also be part of the picture. A possible future marked by the accept of decline, getting accustomed to the approach of death was also at play in their efforts to create a good life in uncertain conditions.

Life seemed to be marked by very different, even contradictory values, and different ways of being with the body. The elderly seemed to be able to navigate across quite different social spaces and moral terrains on a daily basis. As Cheryl Mattingly points out, people engage in practices that draw upon divergent, or even rival, moral schemes in the making of self (Mattingly 2014:155). To highlight the experimental and social aspects of moral becoming, Mattingly coins the term 'moral laboratories'. Moral laboratories are momentary experiments of "how life might or should be lived " (Mattingly 2014:15), experiments of moral becoming. Even though they may take place in quite ordinary places, like training at the local training center, walking the stairs to your apartment or considering the practicalities of the end of life in a conversation with a family member, they address deeply personal projects connected to a sense of who you are as a person.

Moral laboratories is based on the concept of first person virtue ethics which draws on phenomenology and virtue ethics, or neo-Aristotelian ethics. First virtue ethics center on moral matters at the core of what it means to be a human being, according to Aristotle: not only to live, but to live a good life, to thrive. 
Moral thriving is a matter of discerning what roads are worthy of following in life under different circumstances. These conditions may vary from person to person but the process of discerning is not a matter of individual will. The good life is based on common values and the building of character through actions that express certain norms.

As part of a fieldwork among Danish elderly going through physical rehabilitation, I followed training and other activities together with elderly and staff. After a while fieldwork grew into other areas of the lives of eight elderly; in their homes, going shopping, visits to summer houses, social activities and other forms of training. Following the elderly across different settings has shown how life with a frail body is lived and created across different social and moral spaces accentuating different ways of being with the body. In the training centers core values of being an active and independent person were practiced through exercises and standardized tests aimed at bringing the body back to a higher level of physical function. However, experiences of decline and the end of life were also part of their lives and creating a good life with frailty, and even a good death, co-existed with the active efforts of improving the body.

As Mattingly points out, we need to study moralities not only as beliefs put into words, but in the "embodied manner in which they are revealed" (Mattingly 2014:156). What this article brings into light is how the ageing and sick body is perceived and constituted across different moral settings, and the relation between body and self. We experience the world through our bodies, and our bodies are the primary means of engaging with the world (Merleau-Ponty, 1945). Human experience is fundamentally incarnated, or embodied (Csordas, 2003). This is also referred to as a body-self (Lock \& Shepher-Hughes, 1987). When the body changes, for example when it falls ill, it has fundamental consequences for our sense of self. At a practical level, it means that we have difficulties doing the same things as we used to. Ordinary routines we consider part of life can become major physical challenges or even impossible to do anymore. The meaning of the ill body is uncovered through trying to manage daily activities and no longer being able to (Charmaz, 1997). Working on improving the body and practicing the performance of daily activities is also a moral project, a matter of creating, and recreating, oneself as a specific kind of moral character. Ideas of what constitutes a good life are challenged when the body can no longer function in a way that supports those ideas. A predominant ideal for elderly people is to live an independent, active and healthy life as long as possible. In this way, the frail body presents not only a bodily crisis, but also a moral dilemma. Training the body in the training center 
and at home is at the core of a personal 'ground project' (Mattingly, 2014:12) and a moral striving to create a good life in tune with their perceptions of what kind of person they would like to be. Furthermore, training was a series of practices that brought forth a perception of the body as a controllable and malleable object.

\section{The training center: Exercises, tests and 'body-experts'}

Working with the body was not only a question of improving functional ability but was deeply connected to so-called 'ground projects', a notion Mattingly draws from Bernard Williams in order to bring first person virtue ethics one step closer to the person living in a specific, moral world. Ground projects involve "deeply cherished and self-defining ideals, activities and personal associations" of such a character that people would not know themselves without them (Mattingly 2012: 310). What is at stake for the elderly is not only being able to simply perform certain activities of daily living, but to be able to perform activities by which they create a familiar everyday life and a known sense of self. Many longed for and hoped again to become the person they used to be, and to be able to do the things they used to do. The possible future one strived for was inherently informed by notions of the past making their ground projects seemingly fraught with a sense of future nostalgia.

The ways of working with the body in the training centers were characterized by standardized exercises, questionnaires and tests. In the initial interview, questions based on the questionnaire Activities of Daily Living (ADL) would often be used to make suggestions of goals by asking the elderly during the first interview to describe their everyday life in more detail: "what about shopping?", "what about cooking?", "what about bathing?" For a goal to be useful it had to be both specific, realistic and make sense for the person working towards it, for example: "To be able to take up shopping at the local supermarket again." Different tests and tools, eg. $\mathrm{COPM}^{1}$ (Canadian Occupational Performance Measure), ADL (Activities of Daily Living) and SFT (Senior Fitness Test) would also be employed to evaluate functional ability and the ability to perform daily tasks. The Senior Fitness Test that measures balance, strength in arms and legs, agility and endurance was used to perform a baseline test that could be used to evaluate progress during and after training. During training, progress was carefully monitored through documentation of the increase in number of kilos and repetitions in the individual training programs. Some exercises were performed individually in machines and others 
performed in groups. While all exercises were designed to strengthen the body in order to better be able to better perform daily activities, some of them seemed like a direct miming of routine movements. This could for example be to walk the stairs guided by a therapist, or to get up from and sit down again on a chair. Another example was hanging up simple pieces of laundry in the form of dry cloths which involved stretching, keeping one's balance and managing the fine movements of placing a clamp on the "clothesline". It seemed like the training sessions became a rehearsal studio for life outside the center.

The entire training course took place under the guidance and continuous motivation from therapists, who functioned as a sort of 'body-experts'. Their part was not only to evaluate functional ability through interview, tests and monitoring the progress from session to session, but also to help interpret new and unfamiliar bodily sensation that would arise during training. The recovering and in some cases post-operative body could make itself known through sudden pains, dizziness and feelings of exhaustion. Performing the training exercises would for many also be an unfamiliar way of moving the body, and the concept of having to push one's limits to get results. The uncomfortable, physical sensations involved in pushing those limits would add to a feeling of moving on unknown terrain, not sure how far one would be able to go.

The therapists would facilitate and translate the bodily sensations, offering ways of understanding what was going on with the body and how to act accordingly. Pain could for example be interpreted as either good or bad. A 'good pain' was the body's signal that its limits were being pushed and things were moving in the right direction. A 'bad pain' was a signal that things were moving too fast and it was time to take a rest. Interpreting a 'good pain' as a 'bad pain' would mean that one would take a rest during training when it was actually time to move on in order to get the results aimed for. Therapists would continuously educate the elderly in these differences whenever pain or other signs of discomfort would show up during training, offering a framework for understanding the body and how to deal with it.

\section{Healthy and active seniors}

Working to keep one's body fit and being able to uphold an active and independent senior lifestyle is a moral project at the core of what it means to be a morally good, elderly person, and to age well (Gilleard \& Higgs, 2000; Katz, 2000). In this 
sense striving to be able to do the everyday things one has been able to earlier can also be seen as a way of creating oneself as a person living the kind of old age that is valued positively. Elderly, their family and therapists would all equivocally talk about keeping fit and to "keep going" as the thing to strive for. The ideal of the active and independent elderly was a highly motivating force and a framework for interpreting the experience of the bodily changes.

In his analysis of the formation of gerontological knowledge Stephen Katz shows how ageing takes place within a moral nexus of activity, health, and independence, where perceptions of the good life is connected to maintaining a certain level of physical functional ability (Katz, 2000). High physical functional ability have become the new 'normal' (Katz \& Marshall, 2004). In this way, cultivating character is connected to a moral demand of cultivating body and mind through certain activities. Studies of ageing and eldercare in Denmark has explored how this ideal plays out in policy and practices aimed at keeping the elderly population as healthy and active as possible, physically as well as socially, both related to attempts of regulating public health care costs and the managing of elderly citizens (Bülow 2013, Lassen 2014, Mikkelsen 2017). It is an example of what Foucault termed governmentality and practices of biopower by which the elderly body is managed and framed within a moral demand to stay active and healthy. As sickness and frailty demarcates the elderly body as 'non-civilized' and signals a crucial lack of control that consequently signals a moral weakness, or 'un-civilized' person (Lupton, 1995), the training center can be seen as a key site for managing frail, elderly bodies and getting them back to a civilized state.

The body in the training center is a regulated body subject to standardized test and exercises, a regulated and controllable entity crafted through individually designed training programs aimed at fixing the parts and functionalities of the body that are not living up to standards - knees, hips, balance, level of strength. It is a predominant notion of the body within the moral claim to stay healthy and active that the body is fixable, like a machine with broken parts, a predominant biomedical metaphor (Lupton, 1995; Mattingly, 2014).

Phenomenologically, the experience of illness and frailty has been described as resulting in a distance, a split, between body and self (Leder, 1990). This gap between 'outer' body and 'inner' experience, or sense of self, has also been described as a sort of prison for the captured self (Gadow, 1992; Kofod, 2008). With the theory of the 'Mask of ageing', Sharon Kaufmann similarly describes a fundamental aspect of the aging process itself as the body not corresponding to one's experi- 
ence of 'inner self' (Kaufmann, 1986). Working on the body as a controllable entity might also perpetuate this type of experience even further.

As moral terrain the training centers share core characteristics with the type of moral inaugural scene which Mattingly terms 'the artisan's workshop' (Mattingly, 2012, 2014). The artisan's workshop highlights the practices by which people cultivate a certain moral character through self-discipline and training under the guidance of experts. In the training centers the careful and systematic crafting of healthy, aged bodies through tests and exercises under the guidance of a group of 'body-experts' fits readily into a Western, neo-liberal paradigm bringing forth the image of an independent and active subject and one of the key driving forces behind notions of successful and healthy ageing.

\section{Training outside the training centers}

The disciplining of the body and crafting of the active and healthy self through activities and specific training routines was not a practice limited to the training center. Everyday activities would assume training status as minor, momentary experiments of moral becoming. Walking the stairs was not just walking the stair, one elderly woman, Signe, explained to me, "it is also training!" She would explain how far up she could get before having to take a break on the stairs, and how that would serve as measurement for how she was doing. Going shopping had also become part of her everyday training. She had chosen to spread her shopping activities over several days in order to get out of the house as many days as possible. She had learned that she was no longer able to walk the entire way to the supermarket like she used to. Instead she had found a way which included taking a bus close to her home, getting off again after a couple of hundred meters, and then walking the rest of the way. In this way she could go shopping without getting too exhausted, a high price to pay. These examples show how everyday routine situations can turn into a moral lab, a site for experimenting with becoming - once again - the active person Signe knew herself to be, turning the stairs to her apartment and the trip to the supermarket into training settings.

Actual training exercises would also make their way from the training center to the home and, with varying success, be adopted as part of everyday routines. This would add to the changing of everyday routines into training with a purpose, and attesting to the growing blurring of boundaries between clinic and home as health care practices increasingly move into the home sphere (Grøn, Mattingly 
\& Meinert, 2011). By her therapist, Signe was given exercises to perform at home between the training sessions, but even though it seemed like a good idea to her, she didn't manage to create a regular routine with the exercises. Taken out of the context of the training room, with no other people to train with and no therapist to encourage her, she lacked the motivation to do the exercises. In her home setting the exercises even seemed ridiculous to her, as she illustrated to me by walking across the living room, her knees held up high for each step, her balance challenged because she was laughing at the same time. As exercises change context they attain new meanings, as Grøn, Mattingly and Meinert show in their analysis of 'chronic homework' (Grøn, Mattingly \& Meinert, 2011).

While everyday routines would attain new meaning as regular training exercises, exercises that did not seem to mold easily into everyday routines or movements would not last. Also Signe's home would carry 'left overs' from earlier attempts to incorporate training exercises in daily routines, like the half inflated training ball acquired after an earlier training course aimed at strengthening her back and balance. The ball would linger behind the door to the living room as a constant reminder of the training she felt she ought to do, but wasn't doing, and hadn't done for a long time. In another home I visited often during fieldwork, a device for training the legs no longer functioned as training equipment, but was used as a footrest under the coffee table.

\section{The electrical box and the old fart}

When everyday routines, such as walking the stairs or going shopping, became part of a greater endeavor to return to a known sense of self and to create oneself along the lines of the ideals of healthy ageing as an active senior, it also seemed to move the perception of success and failure one step closer to home, so to speak. Not succeeding with a training course by not reaching your defined goal or, as it also turned out at times, you were not able to follow it through because of a deteriorating health is one thing. Failing at performing your everyday routines is a much more direct reminder of where it had all come to. It is not a goal set in a training center you attend two times a week, it is an integral part of your daily life. From her living room Signe could see an electrical box on the sidewalk across from her building. At times she would observe a man sitting on the box, taking a rest while he was out walking. To Signe, this represented a sort of personal benchmark; when she would no longer be able to walk the street without having to 
rest on the electrical box, it would be a clear sign to her that things had gone really downhill for her. Not yet having to take a rest on the electrical box when walking imbued her with a sense of still going strong. At the same time her story about the box in some sense held the silent expectation that one day she would be the one who would have to use the box as a rest stop.

The high value connected with independence and activity could also be expressed as negative self-evaluation when one did not succeed in keeping standards the way one would like to. "I could never have imagined I would turn into such an old fart!" an elderly woman bursted out one afternoon while we were having coffee in her living room. Before that statement she had explained with a regretful tone how she was no longer able to keep her house tidy in the way she used to, nor go for Sunday walks with her friend as she had done through several years. Only partly through her training course, which was not her first at the training center, she still aspired to get better and yet found her lack of progress frustrating. Measuring herself against her ideals of keeping active and being able to keep a nice home left her in the loosing position as an old fart - a weak and slightly ridiculous figure.

While framing the efforts to stay active both in and outside the training centers solely as an example of the exercise of bio-power exercised through docile bodies brings valuable insights on how the training center functions as a moral terrain and the way the body is cast and worked upon. However, it misses other aspects of what life with a sick and frail body is like. No certainty is given in moral experiments (Mattingly 2014), and for the elderly there was no certainty that the careful crafting of the body in the training center would turn out successful. In this respect, the home, and with it the surrounding environment of the home, serves as an example of a different type of moral terrain, giving way to both a critique of the activity ideal, to another possible future and ways of being with the body, echoing ideas of withdrawal from the active and socially outgoing life as a good way to age.

\section{The infidele body}

Anna lived in a three room apartment in a traditionally working class neighborhood in Copenhagen. She had never married, had no children, and was the last of three sisters. Her only remaining family member was her nephew who she saw a couple of times a month. Anna had lots of stories to tell from her life-long career 
as a leading nurse and her travels, which were frequent topics for the talks she had given at the activity center and the local church. As a former girl scout outdoor life in general, as well as swimming and playing tennis, had held an important role in her life. Within the last couple of years, though, physical activity and even walking had grown increasingly difficult for her. She now preferred not to leave the apartment after nightfall because she felt insecure in the dark streets. "Before", she said, "if someone should try to assault me, I would just run away. Now I'd probably lose my balance and fall".

When talking about what had happened to her during the past year and a half, she often began by telling that she did not need any kind of help before "it all" started. It started one day she suddenly felt a strong pain in her back. On her way to one of her many visits to a folk high school, she decided to go in spite of not feeling well. Her condition worsened during the stay, and one evening she was driven to the hospital. It turned out that a part of her spine had collapsed due to osteoporosis. Back from the hospital, she had a visit from an assessment officer from the local authorities. Anna was assigned cleaning help once every fortnight as well as help with the laundry, and furthermore to three months of physical rehabilitation at the local training center. Unfortunately, she was omitted to hospital once again shortly after, this time due to a reaction to some of the painkilling drugs. She was exhausted and dehydrated. Once again returning to her home from the hospital, she caught the flu and had to cancel Christmas with her nephew. She spent the holidays alone in her apartment while taking penicillin. Once recovered from the flu, she caught a cold after a few weeks.

What Anna and many other of the elderly go through bears resemblance to life with chronic illness, which some of the elderly also deal with on a day-to-day basis, on top of the occasional more acute health issues also making their mark. With the words of medical anthropologist Arthur Kleinman the body "menaces. It erupts. It is out of control. One damned thing follows another. The fidelity of our bodies is so basic, that we never think about it - it is the grounds of our daily experience. Chronic illness is a betrayal of that fundamental trust" (Kleinman, 1988:44-5). Even when going through training exactly as advised by the therapists there was no guarantee that one would reach the defined goal. Both Signe and Anna had gone through more than one training course as the level of physical function they reached would not last. 


\section{'Turning it down a bit'}

In the accounts of the elderly, the body would often be featured as an active entity that could turn into an unreliable actor. Signe said: "Once I fell here at home, twice in two days. It was very strange and no one could really explain why. I couldn't explain it myself either, because I didn't trip over the rug or anything like that..."

As one of the primary reasons for the uncertain conditions in their lives, the body did not always walk the more or less straight line of training exercises towards a determined goal. The body would even seem to work against their plans at times. Signe would for example complain about her leg - that "It doesn't want the same as I do!" as if she and her body had their own separate plans taking them in each their direction. Not only was the body experienced as apart from the self, as Leder has shown in his analysis of the 'dys-functional' body (Leder, 1990). The body could also act seemingly out of its own will, as suggested by the previous quote by Kleinman; it would act as a betrayer.

Seen from this perspective, striving to stay as active as possible and maintaining a known sense of self is much more an endeavour undertaken in constant collaboration with the body than it is a matter of controlling the body. It might be necessary to redefine what you are aiming for and develop alternative strategies that allow you to keep doing the things you are used to, albeit in a different way and within a smaller radius of movement. Anna explained it like this:

"I've had so many different things going on, and I was able to have that without problems, but I can't anymore [...]. I can't do what I used to, that's how it is, but then I try to find other things at a lower level [...]. I only get the paper on Fridays and I study it every time and then I mark the things I would like to go to, it can be a church concert or an exhibition. But then again there's that thing where I have to look at: How is that exhibition? Is it something where you have to walk very far? Or something like that. Then I feel I'm still kind of active, but I've turned it down a bit."

'Turning it down a bit', or decreasing one's circles of movement, is a way of keeping active although not quite on the same scale as earlier. In a similar vein, Anna had also chosen to no longer attend choir practice and reading clubs because she didn't feel she was able to participate at the same level as she used to. She couldn't read the nodes properly, and getting down the stairs to the room where the reading club was held became too much of a challenge. 'Turning it down a bit' was a way 
of coming to terms with the altered body, not in the way one had hoped to, but the way that turned out possible. Withdrawal from activity echoes another theory on ageing, 'disengagement theory', which in the early 1960's voiced withdrawal from both physical and social activities as a natural process for elderly (Cumming \& Henry, 1961). Disengagement theory was widely refuted and theories of activity as the core of a good ageing process came into being.

'Turning it down a bit' was primarily something that was voiced outside of the training center. The private sphere, on the other hand, was a setting in which other moral norms about ageing could be voiced, as well as a critique against the demand to stay active.

Anna had for example been asked to give yet another talk on her life and career at the local activity center adjacent to the training center. The activity center was a place promoting both physical and social activity, and the therapists often encouraged elderly to go there after their training course had ended as a way of staying active. While she liked visiting the activity center and had enjoyed giving the talks, she was also frustrated about the ask for more: "They think I'm doing so well when they see me walking up and down the hallway over there!" In reality attending the activity center a couple of times per week was one of her carefully selected activities and it took a great deal of her energy to go there. Although she understood that staff had asked her out of good intentions she was still frustrated with what she felt was a lack of understanding of how little energy she really had, and the priorities she had to make. It didn't seem like a kind of conversation she felt she could have with the staff, either.

In the process of 'turning it a bit down', chronological age could be used as an explanatory factor providing reasonable justification for the state of things. Even though Anna had to quit several of the outgoing activities she had loved for decades she would still say with a sense of gratitude: "I don't think you can ask for more - all these parts have worked for you in 90 years, I think that's quite an accomplishment!"

Chronological age could also, as it did for Signe, serve as a means of comparison with other people her age, whom she knew "were doing worse" than herself. It became a form of consolation to her during a time where she was still not able to move about as much as she would like to, in spite of her efforts at the training center. It was a way of dealing with the failing body-machine as a more natural part of the ageing process.

In a similar way, death also had a growing immediacy. As a man who recently had gone through a knee operation put it: "I have stopped to think 'if I die', and started 
to think 'when I die'". Going through ups and downs with a body that does not always collaborate opened up for another possible future, one in which one no longer was alive.

\section{Rehearsing death}

On a visit to Signe's summer house I noticed that the key to the house had a paper sticker with the name of the local town attached to it. She had put the sticker on for the sake of the ones who would have to "clean up after her" after she was gone, namely her daughter. In her apartment in Copenhagen, Signe had similarly embarked upon a major project of sorting and giving away her things, so her daughter wouldn't have to go through the trouble of doing that. Signe tried to give away many of her books, desiring for them to be used, not become trash after her death. For her this was a way of coming to terms with her death and to try to exercise some sort of control with her belongings after she was gone.

For Anna, the awareness of the end of life approaching was also highly present: "When you are 89 years old and look at these hands, you see that you don't have so much time left..."

For her the most pressing matter was that of preparing her nephew Christian for her death. She told me:

"I've been very open about it and I think a lot about Christian, because when I'm gone he's going to be alone. He hasn't founded a family, so I've tried to do everything I can to arrange things so... He'll be alone with all of it! [...] And I've tried to go through it with him, and I've given him my birth certificate and other things, and I've tried to collect it all in some folders. [...] I'm giving him some good advice: 'So, when I'm not here anymore, Christian, then you have to get a moving company to... But first you need to sort out the paperwork, and I've got a book where it is all in...'"

She had also talked with him about her funeral and planned it according to his wishes, as well as her own. Apart from the practicalities she had furthermore advised him to find a new confidant after she was gone, for example the local priest. She had also made sure to sign a "Life testament" in which she waved off lifeprolonging treatment. Both from her professional life as a nurse and from losing 
two parents and two sisters as well as friends, she was well aware of what kind of death she wanted, and most certainly did not want.

Planning for the end of life, going through the practicalities in details and advising her nephew how to take care of his emotional needs after her death seemed like a way of rehearsing and preparing her death together with him. I was moved by the level of care she had for him and impressed by her ability to calmly envision and orchestrate events even after her own death. This was a future in which the hope to improve the frail body had been abandoned and moral values about how to die well had come into play.

\section{Conclusion}

Following the ups and downs of the lives of elderly like Anna and Signe across different settings has shown how they draw upon very different, even contrasting, moral values of how to age well and how to be with the body. Contrary to how the managed and controlled body is actively shaped in the training centers, the body is an active partner that can show up with other plans. This points to a fundamental human condition: to both be an acting subject as well as someone who is the subject to the uncontrollable (Grøn \& Kuan, 2017). One of the main purposes of the analysis has been to highlights ageing as a process of becoming where the elderly actively seek to create themselves according to what for them is a good life under conditions they are not the master of. I have focused on two different futures at play simultaneously, meaning that moral experiments can take on very different directions - both working to stay active and preparing for the end of life. The moral efforts of the elderly attests to the moral pluralism that makes up ordinary life as described by Mattingly (2014), and how different social and moral spaces, such as a training center and your home and other private spaces, are characterized by different moral values. Where the training center promote ideals of activity and independence through crafting the body according to specific goals, the private space at home or at a summer house opens up other possibilities for articulating experiences of ending and coming to terms with ageing and the changed body.

The analysis also shows how experiences of frailty and decline, of not being able to live up to the ideals of how to age well, are not articulated in a moral setting such as the training and the activity center with their focus on improving the body and staying physically and socially active. This may not only be a source of feelings of failure and frustration for elderly who do not succeed with their trai- 
ning. It also leads to the question of where it leaves elderly who might be less able to deal with experiences of decline and the approach of the end of life than Anna and Signe. 'Turning it a bit down' was not always an easy choice but also one born out of necessity, trial and error. What for Anna spurred on the choice to no longer attend choir practice was the experience of failing to live up to her own standards as well as her frustration with not having the energy to go there, barely being able to overcome the stairs to the room or even to read the nodes properly any more. Returning to first virtue ethics, assisting elderly people in discerning what roads to take in the creation of a good life from their point of view when the body challenges sense of self, and you may desire to stay active at the same time as you have to deal with experiences pointing towards the end of it all, would be an approach that does not do away with the unruly, messy and even contradictory aspects of late life with a sick body, but rather embraces it and offer support along the way.

\section{Notes}

1. Canadian Occupational Performance Measure is a standardized tool used to measure perceived changes in time in the performance of specific activities.

\section{References}

Bülow, M. (2013): Unsettling successful ageing. A history and queering of the concept of successful ageing in ageing research. Copenhagen, Denmark: Medical Museion.

Charmaz, K. (1997). Good days, bad days. The self in chronic illness. New Brunswick, USA: Rutgers University Press.

Csordas, T. J. (2003). Embodiment and Experience. The Existential Ground of Culture and Self. Cambridge, UK: Cambridge University Press.

Cumming, E. \& Henry, W. (1961): Growing Old: The Process of Disengagement. New Yourk, USA: Basic Books.

Gadow, S. (1992): Recovering the Body in Aging, In N. S. Jecker (Ed.), Aging and Ethics (113120). New York, USA: Humana Press.

Gilleard, C. \& Higgs, P. (2000). Cultures of Ageing. Self, citizen and the body. Essex, UK: Pearson Education Limited.

Grøn, L. \& Kuan, T. (2017). Introduction to »Moral (and other) Laboratories«. Culture, Medicine, and Psychiatry, 41, 185-201. https://doi.org/10.1007/s11013-017-9534-y

Katz, S. (2000). Busy bodies: activity, ageing, and the management of everyday life. Journal of Ageing Studies, 14, 2, 135-152. https://doi.org/10.1016/S0890-4065(00)80008-0 
Katz, S. \& Marshall, B. L. (2004). Is the Functional 'Normal'? Aging, Sexuality and the Bio-marking of Successful Living. History of the Human Sciences, 17, 1, 53-75. https://doi. org/10.1177/0952695104043584

Kaufmann, S. (1986). The ageless self. Sources of meaning in late life. Wisconsin, USA: University of Wisconsin Press, Madison.

Kleinman, A. (1988). The Illness Narratives. Suffering, Healing and the Human Condition. New York, USA: Basic Books.

Kofod, J. (2008). Becoming a nursing home resident. An anthropological analysis of Danish elderly people in transition, Ph.d. Copenhagen, DK: Department of Anthropology.

Lassen, A.J. (2014): Active ageing and the unmaking of old age: The knowledge productions, everyday practices and policies of the good late life. Copenhagen, Denmark: University of Copenhagen

Leder, D. (1990). The Absent Body. Chicago, USA: The University of Chicago Press.

Lock, M. \& Shepher-Hughes, N. (1987). The mindful body. A prolegomenon to future work in medical anthropology. Medical Anthropology Quarterly, 1, 1, 6-41. https://doi. org/10.1525/maq.1987.1.1.02a00020

Mattingly, C. (2012): Two virtue ethics and the anthropology of morality. Anthropological Theory, 12, 2, 161-184. https://doi.org/10.1177/1463499612455284

Mattingly, C. (2014). Moral laboratories. Family peril and the struggle for a good life. Oakland, USA: University of California Press. https://doi.org/10.1525/california/9780520281196.001.0001

Merleau-Ponty, M. (1945). Phenomenology of Perception. London, UK: Éditions Gallimard, Routledge.

Mikkelsen, H. V. (2017): Never too late for pleasure. Aging, neoliberalism, and the politics of potentiality in Denmark. 